\title{
Suitability of Mortars Produced using Laterite and Ceramic Wastes: Mechanical and Microscale Analysis
}

\author{
Awoyera, P. O. ${ }^{\mathrm{a}, \mathrm{b}^{*}}$, Dawson, A. R. ${ }^{a}$, Thom, N. H. ${ }^{\mathrm{a}}$, Akinmusuru, J. O. $^{\mathrm{b}}$ \\ aDepartment of Civil Engineering, Faculty of Engineering, University of Nottingham, University \\ Park, Nottingham NG7 2RD, UK

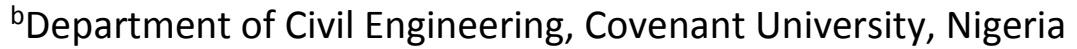 \\ *Corresponding author's email: paul.awoyera@covenantuniversity.edu.ng
}

\begin{abstract}
Using industrial wastes and local materials as artificial aggregates in cement based materials remains a relevant measure for conservation of natural sources. In this study, novel cementitious mixes containing pulverized ceramic blended cement, ceramic aggregate and laterite were systematically combined to produce cement mortars. The mortar specimens were cured in water for a maximum of 28 days. At maturity, nondestructive tests, X-ray CT scan and Ultrasonic pulse velocity, were performed on hardened mortars. Thereafter, a series of predefined properties, namely dry bulk density, compressive and flexural strength, water absorption coefficient (due to capillary) of the hardened mortars were determined. Finally, in order to understand the hydration mechanism of the materials as it relates to the strength properties, microscale tests, SEM and XRD, were used to examine the fragments of the selected mortars. From the results, a mortar sample containing $10 \%$ ceramic powder and 100\% ceramic aggregate as replacements for cement and sand respectively, gave higher strength values than the reference and other mixes. Microstructural analysis of the best mix revealed that it has larger proportions of ettringite, portlandite and calcite than the reference mix, and this could be responsible for the strength
\end{abstract}


gained. Thus, despite the apparent low reactivity of crushed ceramic material, this can improve bonding in cement-based mixture, when used at an appropriate concentration.

Keywords; ceramic waste, laterite, microstructural analysis, pozzolan, strength properties, mortar

\section{Introduction}

The last few decades have witnessed several investigations involving the use of new materials which can replace the conventional materials for concreting. These new materials are selected for investigation either because they are abundantly available or, in the case of waste materials, because they constitute a nuisance to the environment. Both aforementioned reasons are the motivations for the current study. Laterite is an abundant soil material normally found in subSaharan African countries and, for decades, it has been utilized for production of bricks. On the other hand, during production of ceramic tiles, about $30 \%$ of the materials used unavoidably end up as waste. Also, ceramic wastes are found as part of construction and demolition rubble. Therefore, the aim of this study is to make use of both laterite and ceramic materials as substitutes for sand and cement in making mortars.

In recent years, mortars made with various modified materials have been investigated [1-15]. Such studies have been conducted in a quest to find alternative materials which can replace depleting natural materials. However, approval for such materials is subject to whether their physical and engineering properties match those of conventional sources. 
Due to sharp edges of its particles, broken coarse aggregate is viewed as a hazardous waste. Thus It would constitute an environmental benefit if ceramic, which is a hazardous wastes, can be incorporated into making mortar or concrete. Whether it is possible to obtain such a benefit may depend on the particular ceramic supply because, the performance of ceramic products can vary depending on the source. Ceramic products possess varying properties due to the different conditions and composition of materials used in their production.

Studies such as $[12,16-18]$ have explored the suitability of sanitary wares, white and red ceramic as aggregates in mortar and concrete. Thus, it has been established that these ceramic products could replace natural aggregates in concrete, due to the observed strength performance of such concretes. Furthermore, the improved properties of concrete with ceramic can be attributed to the high specific surface of ceramic [13], as well as the high concentration of silica $\left(\mathrm{SiO}_{2}\right)$ and alumina $\left(\mathrm{Al}_{2} \mathrm{O}_{3}\right)$ in ceramic amorphous phase $[19,20]$. As a result, the pozzolanic reactivity of ceramic in concrete can be enhanced.

In recent years, advancement in research has led to the innovative use of laterite or lateritic soil as a concrete ingredient, as well as its routine use in brick production. A quantity of laterite ranging from $10-30 \%$ is recommended for a replacement of natural sand in concrete [21, 22], especially when a volumetric mix of 1:1.5:3 (cement; sand; gravel) is to be used. Unfortunately, adding large amounts of laterite to concrete may negate the strength development in concrete, because laterite contains fine clay materials.

Currently, there are quite a number of interesting studies regarding the use of laterite $[21,23$ $25]$ and ceramics $[16,18]$ as replacement for natural aggregates. However, there are no many 
studies [21], which have considered using both laterite and kaolin-rich material such as ceramic or marble products in mortar and concrete. Therefore, the current study is aimed at exploring different combinations of laterite and ceramic fines as a replacement for natural fine aggregate in mortars, and also at identifying the significant effects associated with such combinations on strength and microstructure properties of mortars. To help understand the observed behaviour, the study aims to determine the hydration products of the mortars after being cured for 28 days.

\section{Materials and method}

\subsection{Materials}

The ceramics, which comprised mainly floor and wall tiles, used in this experimental work were sourced from different construction and demolition sites within Lagos and Ota, in southwestern Nigeria. The ceramic sources are from different manufacturers, but they are originally of stoneware ceramic source. The ceramics were washed with water in order to get rid of debris that stuck to the surface, and subsequently they were air-dried for a few days. Thereafter, a hammer mill was used to grind the ceramic into granular sizes of 2 to $4.75 \mathrm{~mm}$. Another portion of the ceramics was pulverized to a powder size of about 50 micron. The laterite used in this study was collected at a depth of about $6 \mathrm{~m}$, from the sidewall of an excavated lateritic soil profile, located within the precinct of Ota, southwestern Nigeria. The laterite was classified as A7-6(7), in line with the American Association of State Highway and Transportation Officials

(AASHTO) system of soil classification. The portion of the soil that passed a $4.75 \mathrm{~mm}$ aperture size was used for the study. Ceramic powder was substituted for cement at $10 \%, 20 \%$ and $30 \%$, laterite and ceramic fines were substituted for sand fines at different percentages. A grade 32.5 
cement was used, which conforms to the regulations of the Standard Organization of Nigeria (SON), regarding mortar production. Also, natural river sand was used as part of the fine aggregates. Finally, drinkable water was used for mixing the mortar constituents. The physical properties of the aggregates are presented in Table 1. As can be seen, the laterite possessed about double the water absorption capacity of river sand or ceramic fines, a result that can be attributed to its high clay content. [26] also made a similar observation while working on laterite stones. However, there is greater closeness in the specific gravity and fineness modulus values of the three materials. The grading curve for the aggregate used is shown in Figure 1 . Also, the particle size gradation for cement and ceramic powder is shown in Figure 2. The ceramic powder particles are finer than the cement. This will facilitate adequate blending of the two materials [27]. The oxide composition of cement, ceramic powder and laterite was determined using X-ray fluorescence (XRF) and the result is presented in Figure 3. The pozzolanic potential of the ceramic powder used was established from a preliminary investigation [28], following the ASTM C618 criteria.

Table 1. Physical properties of aggregates

\begin{tabular}{lccc}
\hline Properties & $\begin{array}{l}\text { River } \\
\text { sand }\end{array}$ & Laterite & Ceramic fine \\
\hline Specific gravity & 2.61 & 2.13 & 2.26 \\
Water absorption $(\%)$ & 2.24 & 4.70 & 2.52 \\
Fineness modulus & 2.24 & 1.80 & 2.20 \\
\hline
\end{tabular}




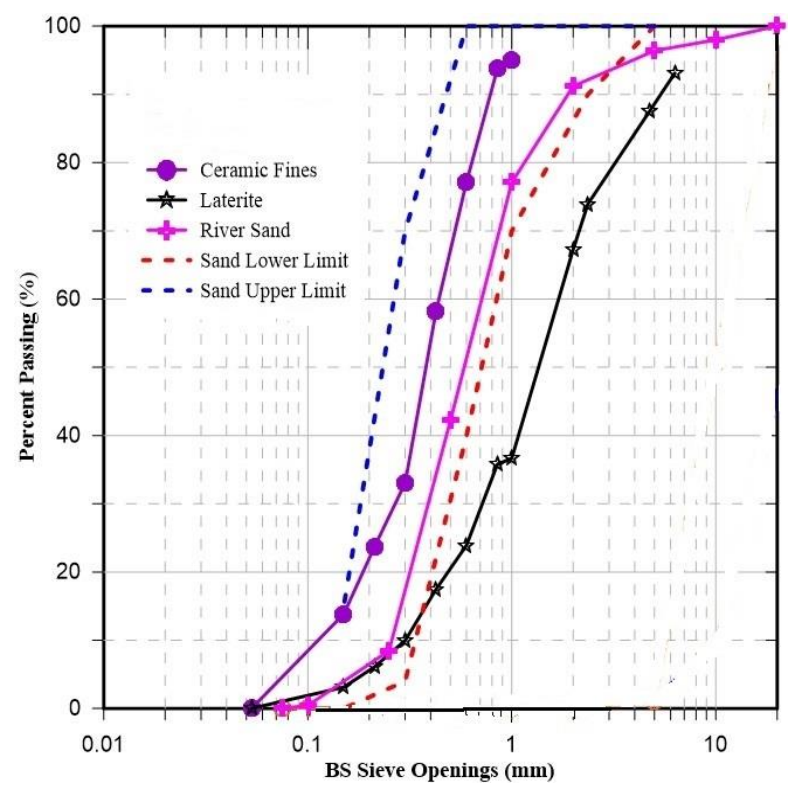

Figure 1. Particle size distribution for aggregates used

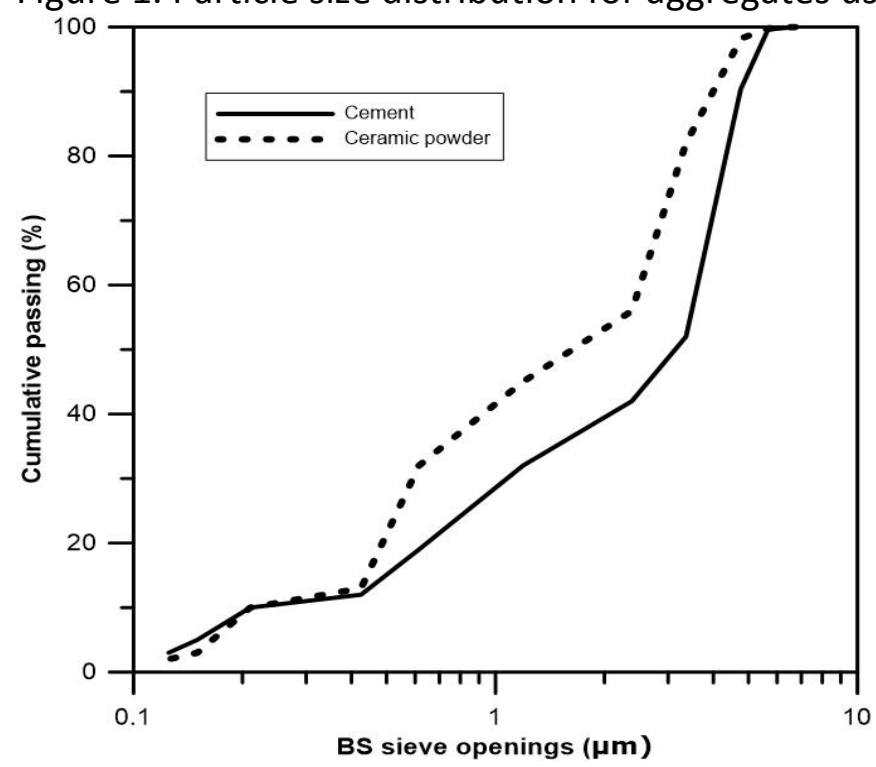

Figure 2. Particle size distribution curve of cement and ceramic powder 


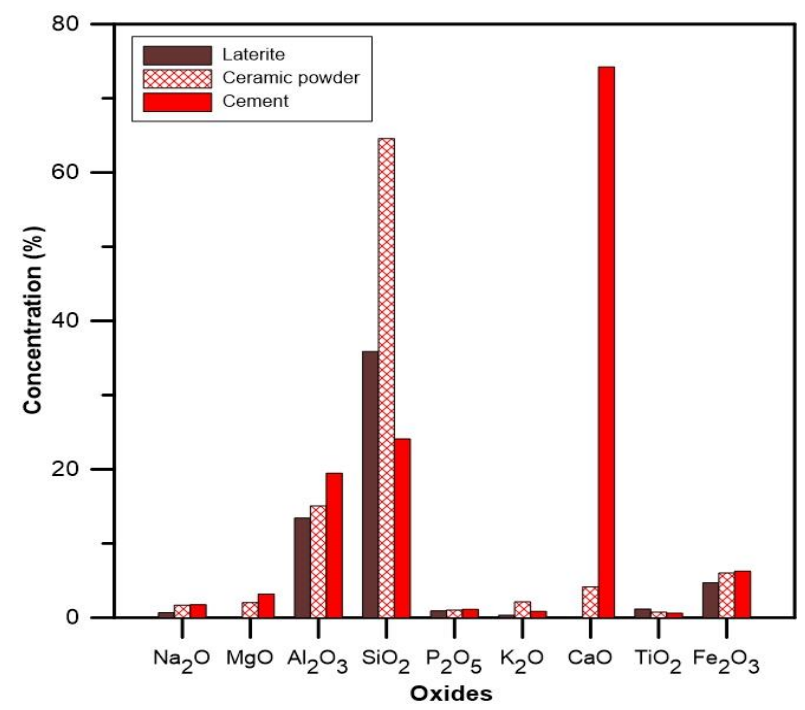

Figure 3. Metallic oxide composition of laterite, cement and ceramics

\subsection{Methods}

Ten mortar mixes were considered as shown in Table 2, one reference mixture (Mref) containing conventional materials for comparison, and nine others containing various combinations of ceramic powder, laterite and ceramic fines. A total of thirty mortar specimens were produced with standard prismatic dimensions of $40 \mathrm{~mm}$ x $40 \mathrm{~mm}$ x $160 \mathrm{~mm}$ in conformity with the requirements of BS EN 1015-11 [29], and the average test results from triplicate specimens was recorded for each mix. Batching was done by weight, using a mix ratio of 1:3 (binder: fine aggregate). The method of batching by weight was selected over the volumetric batching because it takes care of the variations in specific gravity of materials. A constant mixing water-cement $(\mathrm{w} / \mathrm{c})$ ratio of 0.6 was used. This is similar to the mix and $\mathrm{w} / \mathrm{c}$ ratio used in related studies $[1-2,13]$. Mortar specimens were cured in water for 28 days at a temperature of about $21^{\circ} \mathrm{C}$. 
Table 2. Mix proportions for the mortars

\begin{tabular}{|c|c|c|c|c|c|c|}
\hline \multirow[b]{2}{*}{ Mix } & \multicolumn{2}{|c|}{ Binder } & \multicolumn{3}{|c|}{ Fine aggregates } & \multirow[t]{2}{*}{$w / c$} \\
\hline & $\begin{array}{l}\text { Cement } \\
\text { (g) }\end{array}$ & $\begin{array}{c}\text { Ceramic powder } \\
\text { (g) }\end{array}$ & $\begin{array}{l}\text { River Sand } \\
\text { (g) }\end{array}$ & $\begin{array}{c}\text { Ceramic Fines } \\
\text { (g) }\end{array}$ & $\begin{array}{l}\text { Laterite } \\
\text { (g) }\end{array}$ & \\
\hline Mref & 450 & 0 & 1350 & 0 & 0 & 0.6 \\
\hline M10 & 405 & 45 & 0 & 0 & 1350 & 0.6 \\
\hline M20 & 360 & 90 & 0 & 0 & 1350 & 0.6 \\
\hline M30 & 315 & 135 & 0 & 0 & 1350 & 0.6 \\
\hline N10 & 405 & 45 & 0 & 1350 & 0 & 0.6 \\
\hline N2O & 360 & 90 & 0 & 1350 & 0 & 0.6 \\
\hline N30 & 315 & 135 & 0 & 1350 & 0 & 0.6 \\
\hline F25 & 450 & 0 & 0 & 337.5 & 1012.5 & 0.6 \\
\hline F50 & 450 & 0 & 0 & 675 & 675 & 0.6 \\
\hline F75 & 450 & 0 & 0 & 1012.5 & 337.5 & 0.6 \\
\hline
\end{tabular}

After 28 days curing, tests were performed on the specimens in three categories: physical, mechanical and microscale analysis. The physical properties of mortar that were determined are dry bulk density [30] and water absorption by capillary action [31]. Prior to determination of compressive strength and flexural strength [29], which constitute the mechanical properties, both X-ray CT scans (of selected specimens) and ultrasonic pulse velocity (UPV) measurements of all specimens were carried out using an X-ray CT machine and ELE pulse velocity tester respectively. The X-ray CT scan was performed in 2D mode, and the specimens were scanned at $1 \mathrm{~mm}$ intervals. The arrangement for this test is shown in Figure 4. Normally, circular specimens are required for the test, because the sample must fit onto the specimen disc. However, since the mortar samples investigated in this study were prismatic, they were then symmetrically placed in a plastic container, and surrounded by aggregates, such that the sample could be positioned appropriately. Two selected slices of the scans were used to describe the internal structure of the mortars. 


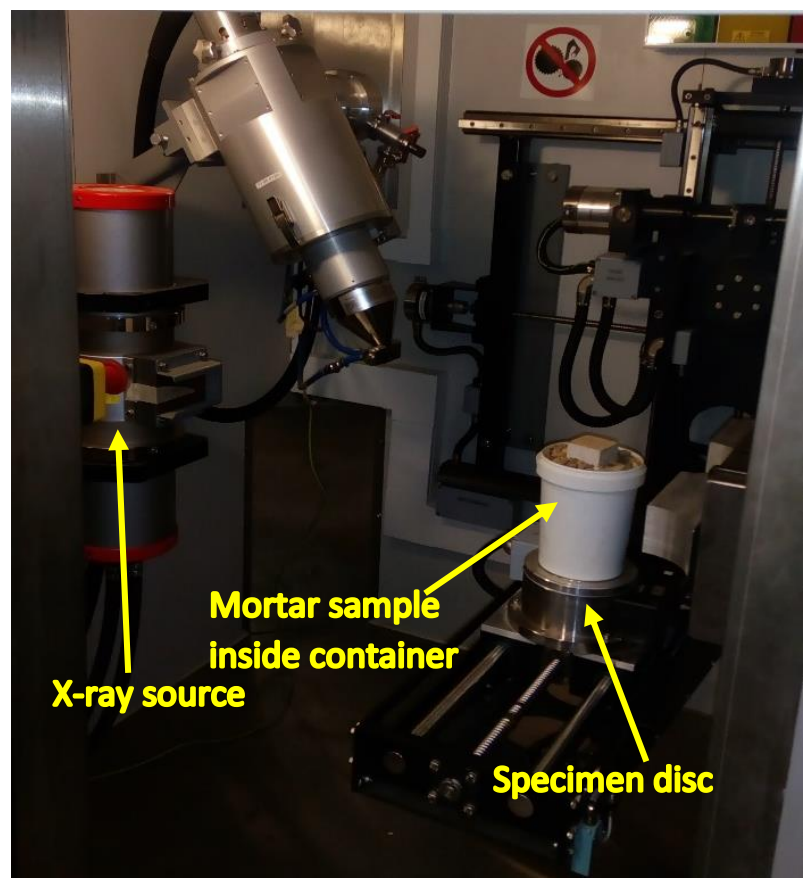

Figure 4. Test set-up for X-ray CT scan of mortar specimen

The reason for the UPV determination was to relate it to the compressive strength of specimens.

The flexural strength test was conducted using the three point loading method, such that the distance between supports was $100 \mathrm{~mm}$ and the load was at mid span, following the requirements of BS EN 1015-11 [29]. During the flexural tests, both the incremental load and corresponding deformations were obtained from a pair of linear variable differential transformers (LVDTs) connected to the universal testing machine (UTM), using a computerized data-acquisition system. The loading was applied at a rate of $0.005 \mathrm{~mm} / \mathrm{s}$ by a UTM with a 200 $\mathrm{kN}$ capacity. The flexural strength of mortars was calculated using Equation 1, as recommended in BS EN 1015-11[29].

$F=1.5 \frac{P l}{b d^{2}}$ Equation 1 
Where $\mathrm{F}$ is the flexural strength in $\mathrm{N} / \mathrm{mm}^{2}, \mathrm{P}$ is the load at failure in $\mathrm{N}, \mathrm{I}$ is the distance between support rollers $(100 \mathrm{~mm}), \mathrm{b}$ and $\mathrm{d}$ correspond respectively to the width and depth of the specimen in $\mathrm{mm}$ (both $40 \mathrm{~mm}$ ). Figure 5 shows the typical setup arrangement for the test.

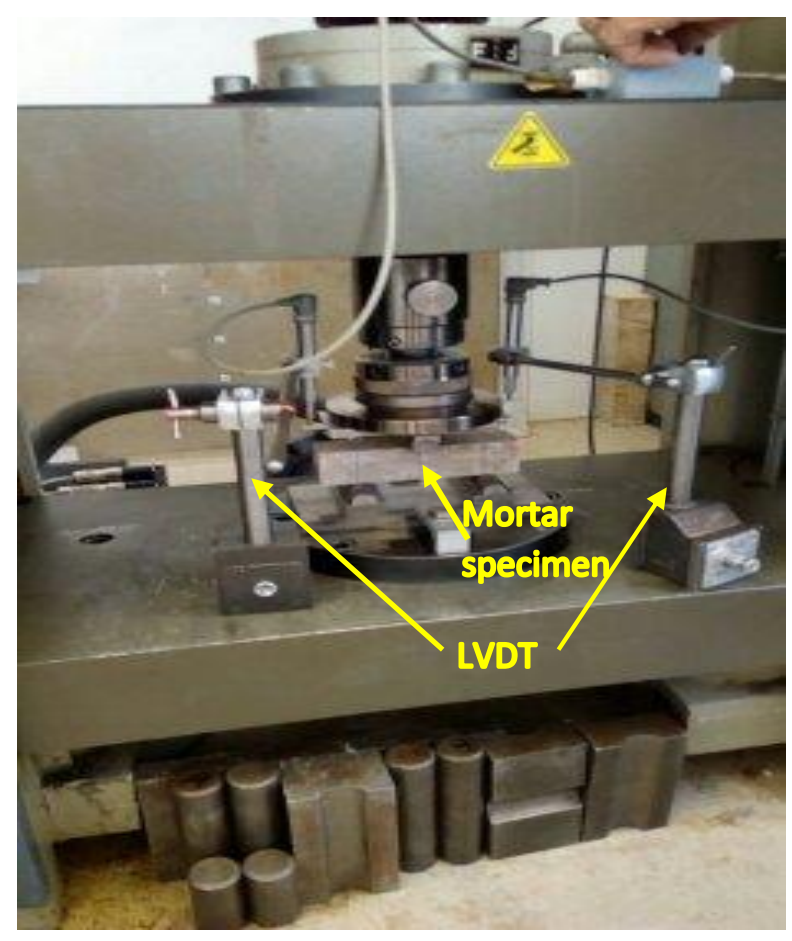

Figure 5. Set-up arrangement for mortar testing

Finally, microscale analysis of selected higher strength specimens was conducted using SEM and XRD tests on parts taken from the crushed samples. The SEM analysis was performed on $2 \mathrm{~cm}$ cube specimens using the wet plotting sample preparation approach. This method does not alter the physical or chemical features of the specimen [32]. One side of the cube was polished with a silicon disc, which makes it flat and further ensures clarity of the images [33]. Specimens for XRD tests were pulverized using a pestle and mortal before they were mounted on an aluminum slide and scanned from 0 to $75^{\circ} 2 \vartheta$ with a scan rate of 0.1 steps per minute. 


\section{Results and Discussion}

\subsection{Dry bulk density}

The dry bulk density (DBD) of mortars was determined following BS EN 1015-10 [30]. It entailed weighing the mass of mortar prisms, which were dried in an oven at a constant temperature of approximately $60^{\circ} \mathrm{C}$ constantly until consecutive weights (within 2 hours interval) were the same. Consequently, the average weight was divided by the volume to obtain the DBD. The results of dry bulk density of mortar specimens are presented in Figure 6. Although there was only slight variability in the DBD of the mortars. However, the density of the reference mortar (Mref) was higher than those of other mixes. The high specific gravity of sand (2.61) is evidently responsible for the higher DBD of the reference mix, than other mixes containing either or combination of laterite (2.13) and ceramic fine (2.26).

When laterite was used as the main fine aggregate in mortars (Mix M10, M20, M30), there wasn't any notable change in DBD. However, some changes were seen in mixes with $100 \%$ ceramic fines (N10, N20, and N30), perhaps because of the packing condition of the particles. Since the DBD for all the samples was above $1300 \mathrm{~kg} / \mathrm{m}^{3}$, they are therefore within the category of normal weight mortar [34]. 


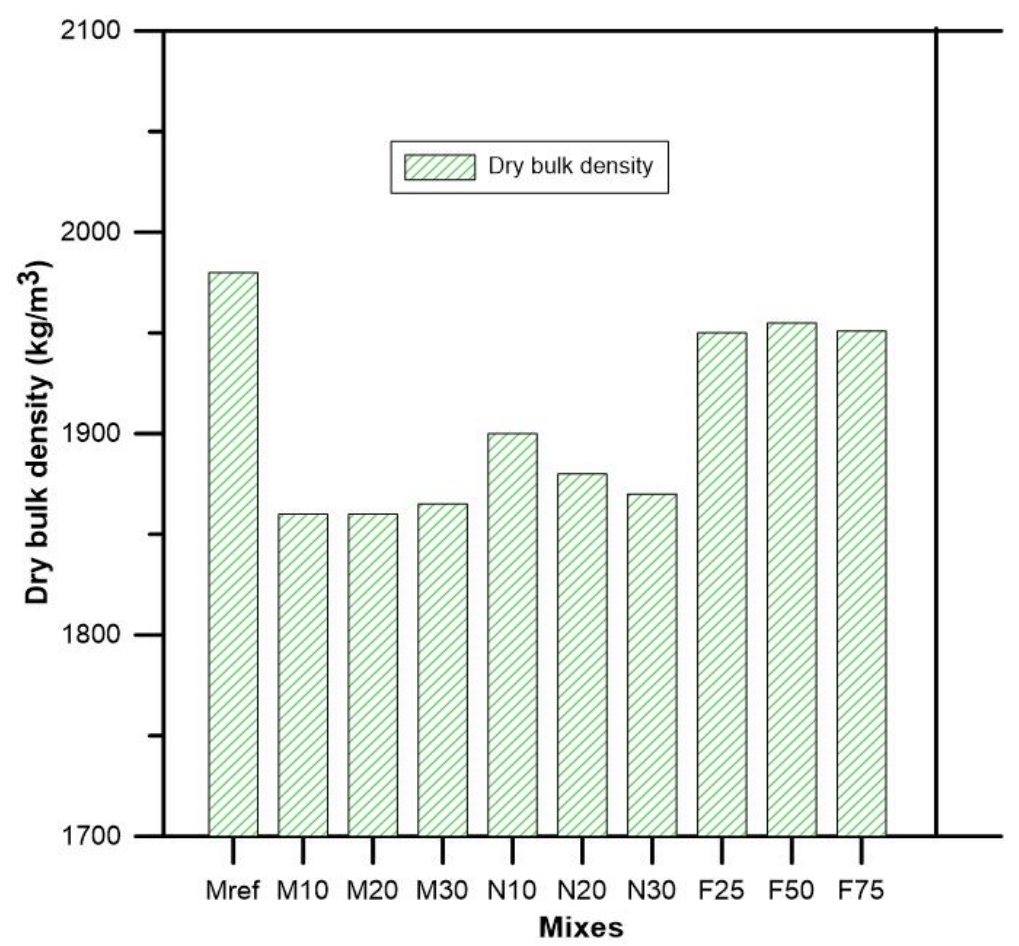

Figure 6. Dry bulk density of the tested mortars

\subsection{Water absorption by capillary action}

Water absorption of mortar by capillary action is a key property as it helps to determine the rate of water ingress into mortar through condensation from the atmosphere, capillary rise from ground water and from driving rain. In this study, broken prisms (approximately $40 \mathrm{~mm} \times 40 \mathrm{~mm}$ $x 80 \mathrm{~mm}$ ) arising from flexural strength tests were used for the determination of coefficient of water absorption by capillary action. The test was performed in conformity with the requirement of BS EN 1015-18 [31]. The results for the water absorption coefficient by capillary action for all mortars are shown in Figure 7. It can be observed that mortars containing $100 \%$ laterite as fine aggregate (M10, M20, M30) present the higher values. This can be attributed to the water absorption property of laterite, which was the dominant aggregate in the mixes. On a general note, Torres and Matias [13] described the increase in the water absorption of a mortar to be as a result of the small pore internal structure of the mixture. However, in the reference mix (Mref) 
and other mixes (N10, N20, N30, F50 and F75, which contain significant amounts of ceramics), the coefficient of water absorption was $\leq 0.85$. These reduced water absorptions were an indication that there were few porous structures in the mixes. During hydration, there is the possibility that cement particles filled up the micro pores extensively.

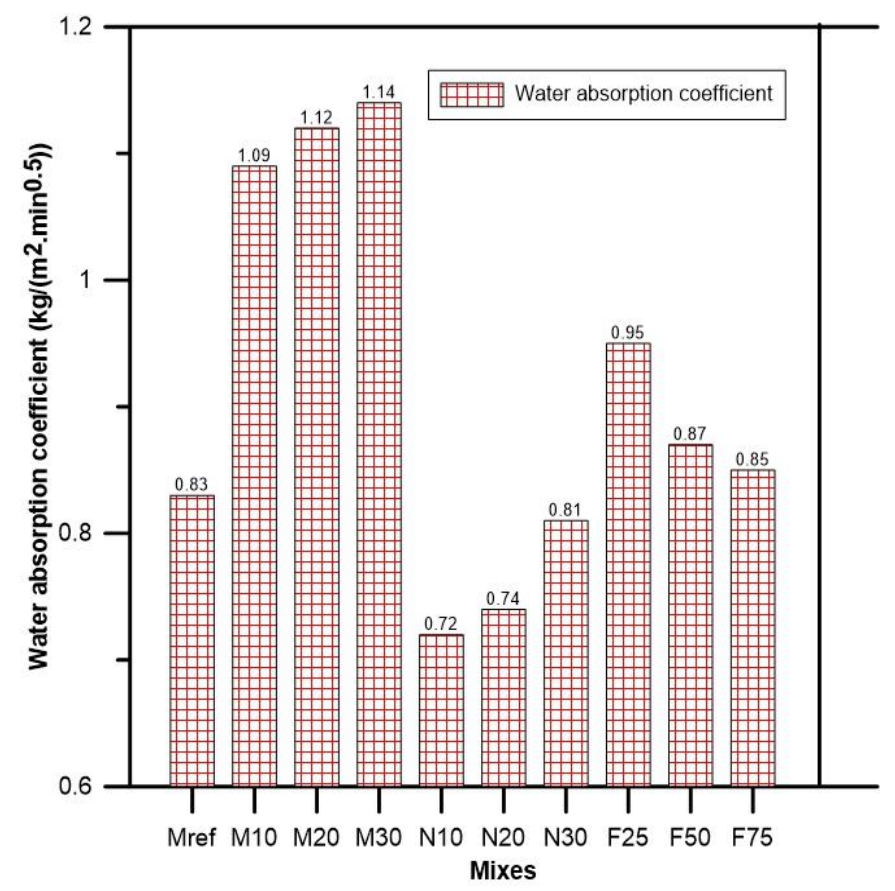

Figure 7. Water absorption coefficient by capillary action for hardened mortar

\subsection{Compressive and flexural strength}

Both compressive and flexural strength tests were used to assess the mechanical properties of the mortar specimens. These two methods are the most commonly used for determination of the strength properties of cemented materials. The results of the compressive strength, and its correlation with UPV values, both obtained at 28 days curing, are presented in Figure 8 and Figure 9 respectively.

As can be seen in Figure 8, the N-mixes (N10, N20, and N30) and mix F75 developed higher compressive strengths than the reference mix (Mref). Ceramic incorporation in the mixes is 
largely responsible for the change in porosity of the mortars, which in turn improved the compressive strengths. The highest compressive strength was developed in mix N10 (having 10\% ceramic powder and $100 \%$ ceramic fine replacement of cement and sand respectively). The strength gained in mix N10 may be as a result of filler action (contributed by ceramic powder which is finer than cement) and the pozzolanic action of the entire mixture. According to Jamil et al. [5] and Chindaprasirt and Rukzon [35], filling actions aid strength improvement in blended cemented materials, and it occurs when the substitute material is finer than the cement particles. With this result, it is evident that that recycled ceramic aggregate and cement paste are well bonded. This observation corroborates the study made on sand dune blended ceramic mortar by Abadou et al. [1].

There is also a tendency for ceramics to speed up the pozzolanic reaction in the mixture that eventually results in the appreciable strength properties obtained. However, for mortars containing laterite, it is noted that the strengths were still lower than reference mortar at all material replacement levels.

The UPV results are presented alongside the compressive strength in Figure 9, so as to deduce the significance of both for the mortar specimens. There was some similarity in the trend of compressive strength and UPV for the samples; as the UPV values increase so also do the compressive strengths and vice versa. Thus, since UPV is measured based on the transit time of an ultrasonic pulse through the solid material, then within the limit of this study, it can be inferred that compactness of cemented materials affects ultrasonic pulse travel time. There exist a strong 
correlation $(r=-0.97)$ between the compressive strength of the tested mortar samples and their UPV values.

The flexural strengths of the mortars are presented in Figure 10. Similarly, just as with compressive strength, the flexural strength of mortars having ceramic fines as the dominant fine aggregate was higher than in other mixes. Also, mix N10 possessed the highest flexural strength. In the mortar specimens containing $100 \%$ laterite as fine aggregate (M10, M20, and M30), both compressive and flexural strengths decreased with increasing ceramic powder. On the other hand, with mortars containing $100 \%$ ceramic fine aggregate, $10 \%$ ceramic powder substitution for cement gave the highest strength, but compressive and flexural strength then reduced as the ceramic powder content increased. Increased alumina $\left(\mathrm{Al}_{2} \mathrm{O}_{3}\right)$ composition as a result of increased ceramic content can contribute to the reduction in strength, excess of alumina being known to weaken the strength of cemented materials [36]. In addition, a $25 \%$ replacement of ceramic fines gave higher strength than the reference mortar, but strength then reduced as the laterite concrete was increased.

The stress versus strain curve of selected mortar mixes is presented in Figure 11. The failure mode of all mortars was brittle-like except for mixes N10 and N20, where the mortars appear somewhat ductile as the loading was increased. It is a common phenomenon that cemented materials would fail by explosive cracking, where loading returns to the zero position (immediately) at failure, but with the incorporation of ceramics, there was improvement in the ductility of the mortars. 


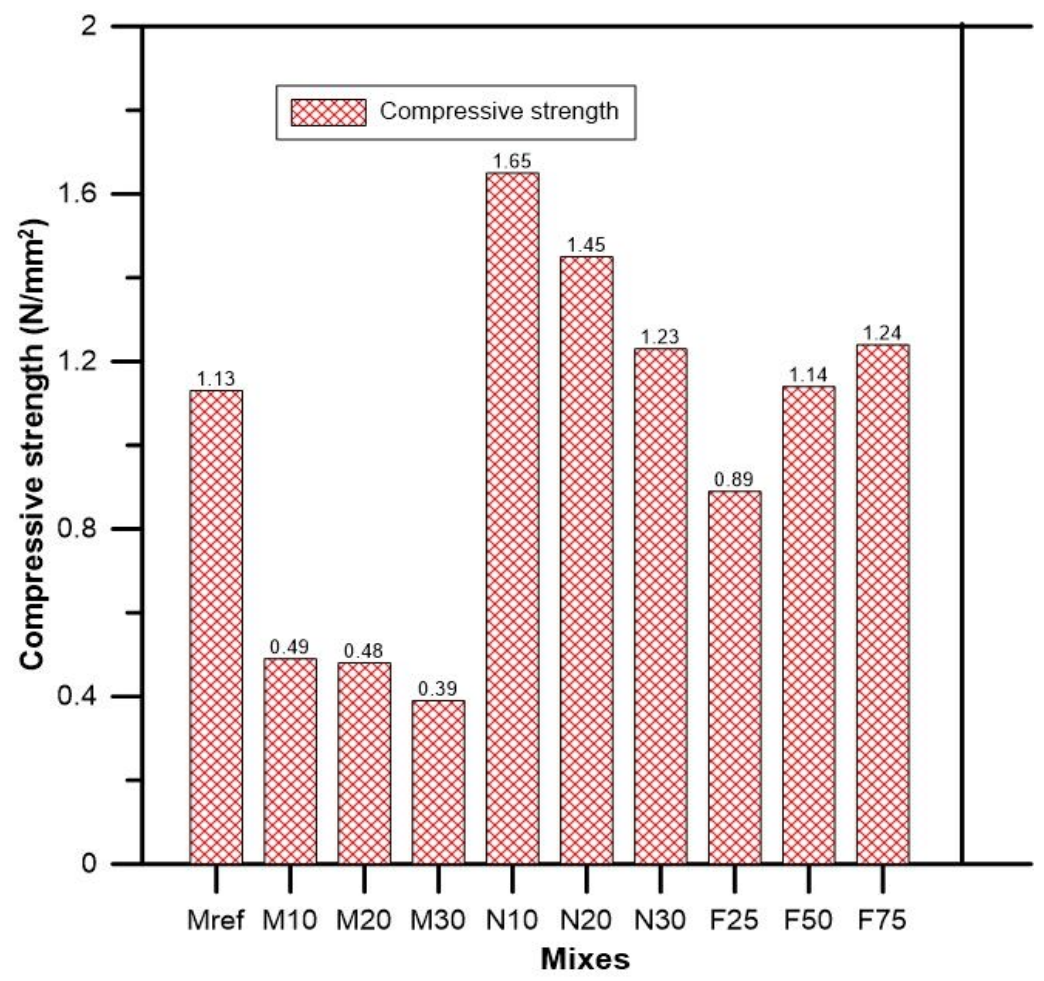

Figure 8. Compressive strength of tested mortars

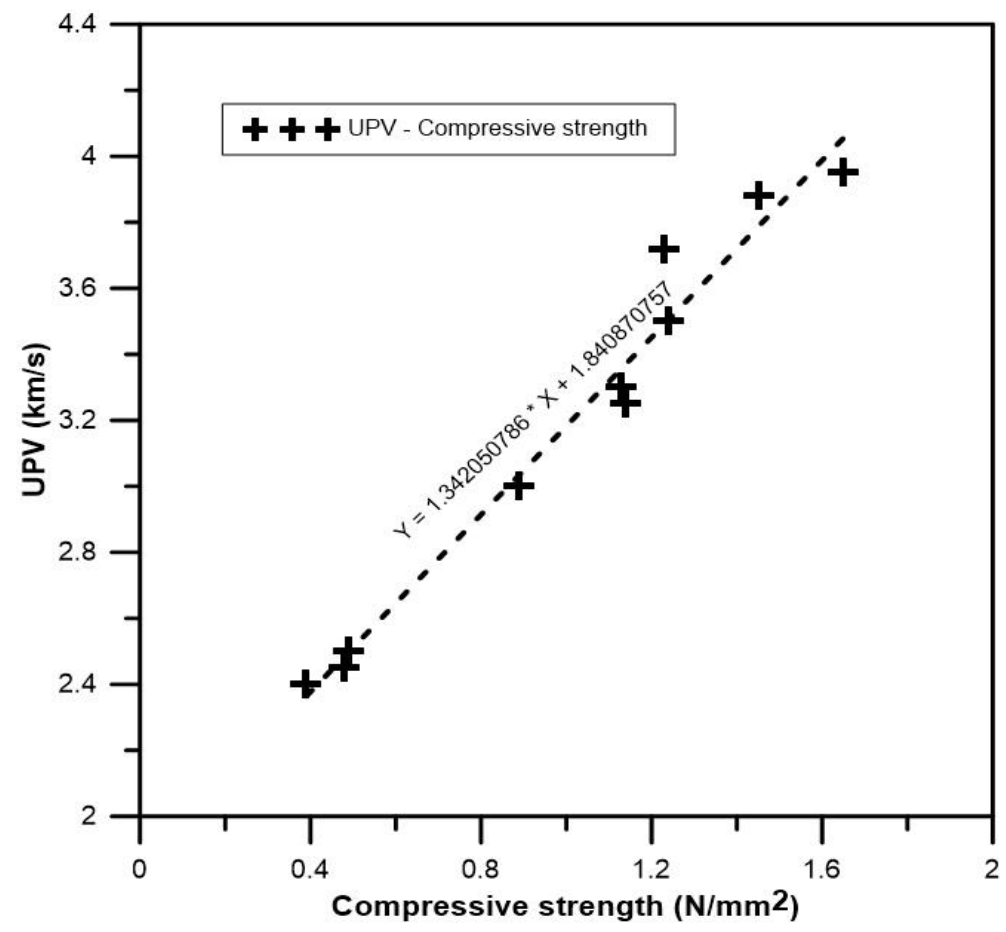

Figure 9. UPV and compressive strength of tested mortar specimens 


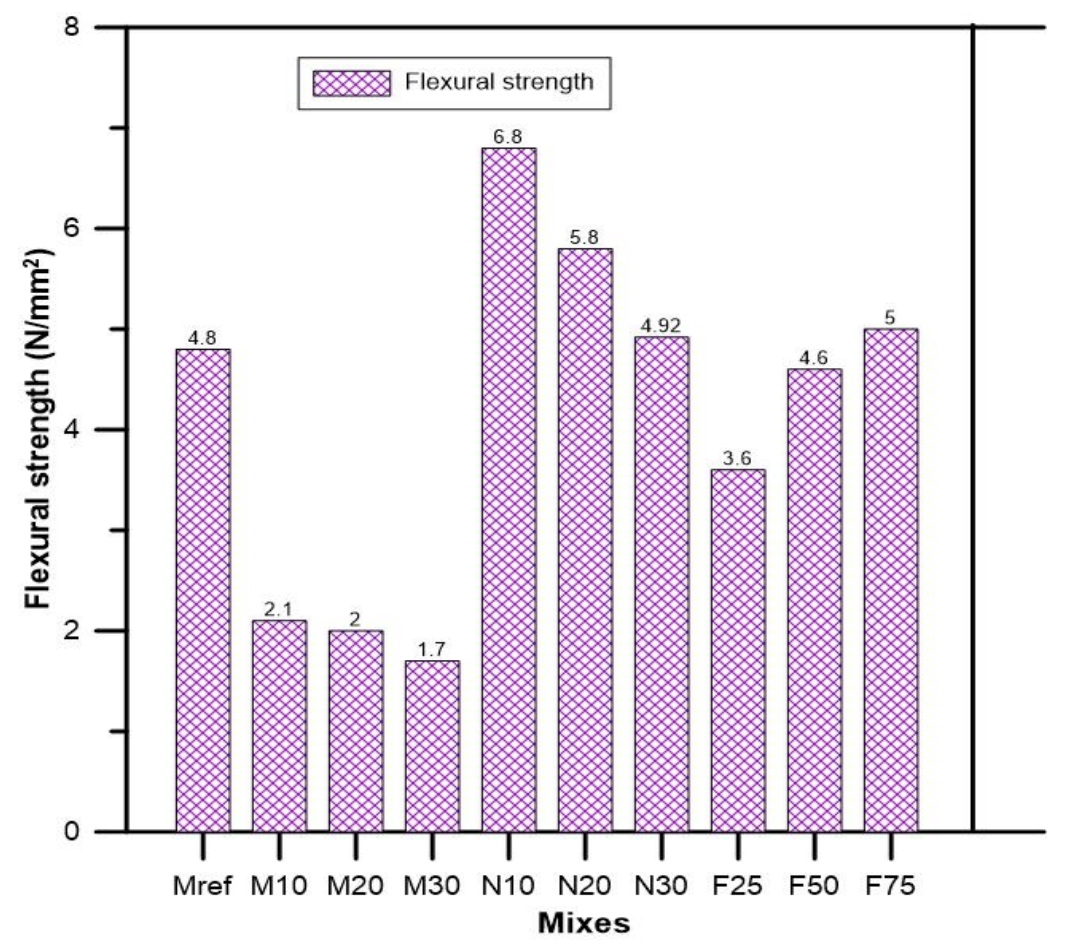

Figure 10. Flexural strength of tested mortars

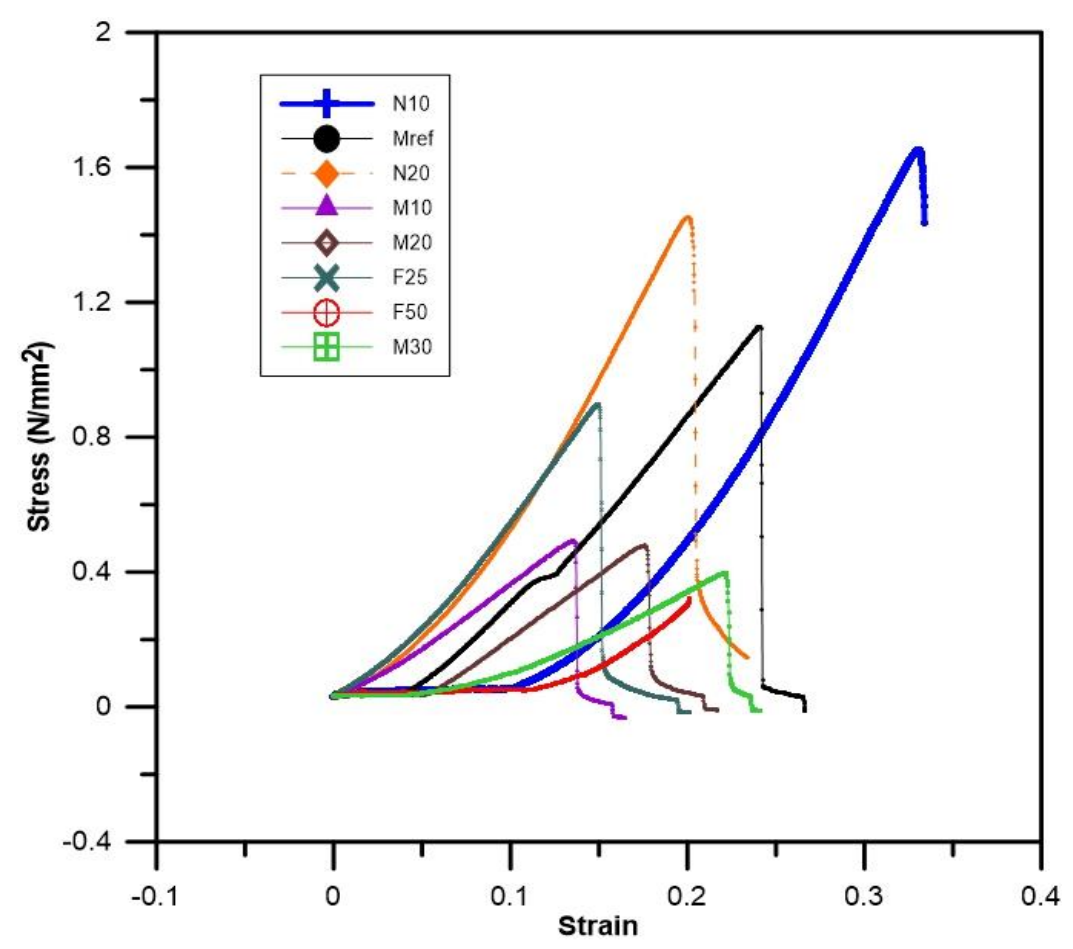

Figure 11. Stress-strain curve of selected mortar specimens 


\subsection{Microscale analysis of mortars}

The intrinsic features and hydration products of selected mortars were evaluated using microscale analysis namely 2D X-ray CT, SEM and XRD. Following the results of the physical evaluation and mechanical characteristics of the mortars, further investigation was performed on the mortar with the best performance (N10) and the reference mortar (Mref).

The XRD of the reference and N10 mortars are presented in Figures 12 and 13 respectively. The observed crystalline phases in the reference mortar include quartz, portlandite, ettringite, dolomite, lamite, gypsum, calcium silicate, and calcite. However, in addition to these phases, N10 also possessed hematite, albite and anorthite. The appearance of high intensity quartz peaks in the two mortars was an indication of pure silica, readily available in sand and ceramics [6, 37]. Therefore, emphasis will be focused on the dominant hydration products of cemented materials. From Figure 12 (Mref) and Figure 13 (N10), the occurrence of ettringite, portlandite and calcite peaks were at $2 \theta$ values $42.5^{\circ}, 34^{\circ}$ and $29.5^{\circ}$ respectively. Higher intensities of these peaks were seen in the N10 mix, which can be due to a more stable pozzolanic reaction, and a result of secondary hydration of calcium silicate hydrate (C-S-H). Furthermore, the hematite, albite and anorthite which are almost absent in the reference are clearly present in the N10 mortar as a result of the pozzolanic reactions between cement grains and ceramic particles. Micrographs and EDS of mix N10 and the reference mix are shown in Figures 14, 15 and 16, 17 respectively. The reference mortar contains large pores and ettringite (Figure 16). However, the N10 mortar shows some capillary pores and CSH (Figure 14). The EDS of N10 mortar (Figure 15) shows a higher amount of oxygen (O), calcium (Ca) and silica ( $\mathrm{Si}$ ), which are in the denser zones. This can be the major explanation for the improved strength properties of the N10 mortar, in that, higher 
amounts of $\mathrm{Ca}, \mathrm{Si}$, and $\mathrm{O}$ in its dense paste zone [5], are responsible for secondary C-S-H gel formation. Consequently, the C-S-H gel reacts with cement hydration product $\mathrm{Ca}(\mathrm{OH})_{2}[5]$. On the other hand, $\mathrm{Ca}$, Si and $\mathrm{O}$ are lower in the reference mix (Figure 17). Again, the observed well developed structure of N10 mortar still buttress on the influence of a good effect from the filler and the pozzolanic action of the ceramic powder and the cement particles.

Finally, the internal structures of the N10 mortar (Figure 18 a) and reference mortar (Figure 18 b) were evaluated using 2D X-ray CT scans. The X-ray CT normally creates images that map the variation of the X-ray attenuation coefficient within an object [38]. As can be seen in Figure 18(a), the N10 mortar contains numerous voids, unlike the reference mortar (Figure 18b) with little apparent void. Higher interconnectivity of the interfacial transition zone (ITZ) between binder (cement and ceramic powder) and the ceramic fine in N10 mortar could be responsible for the increased void content. 


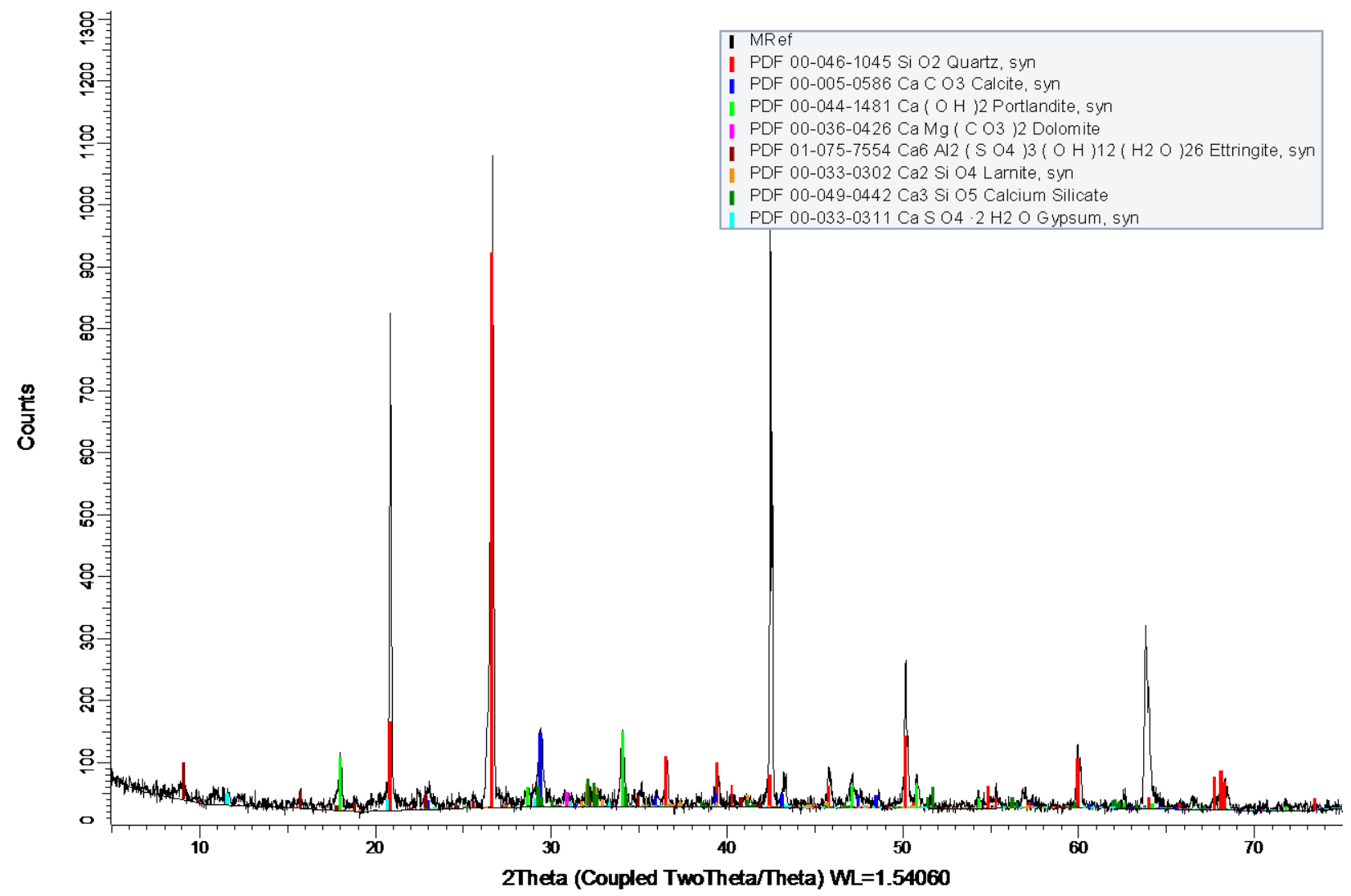

Figure 12 XRD of reference mortar 


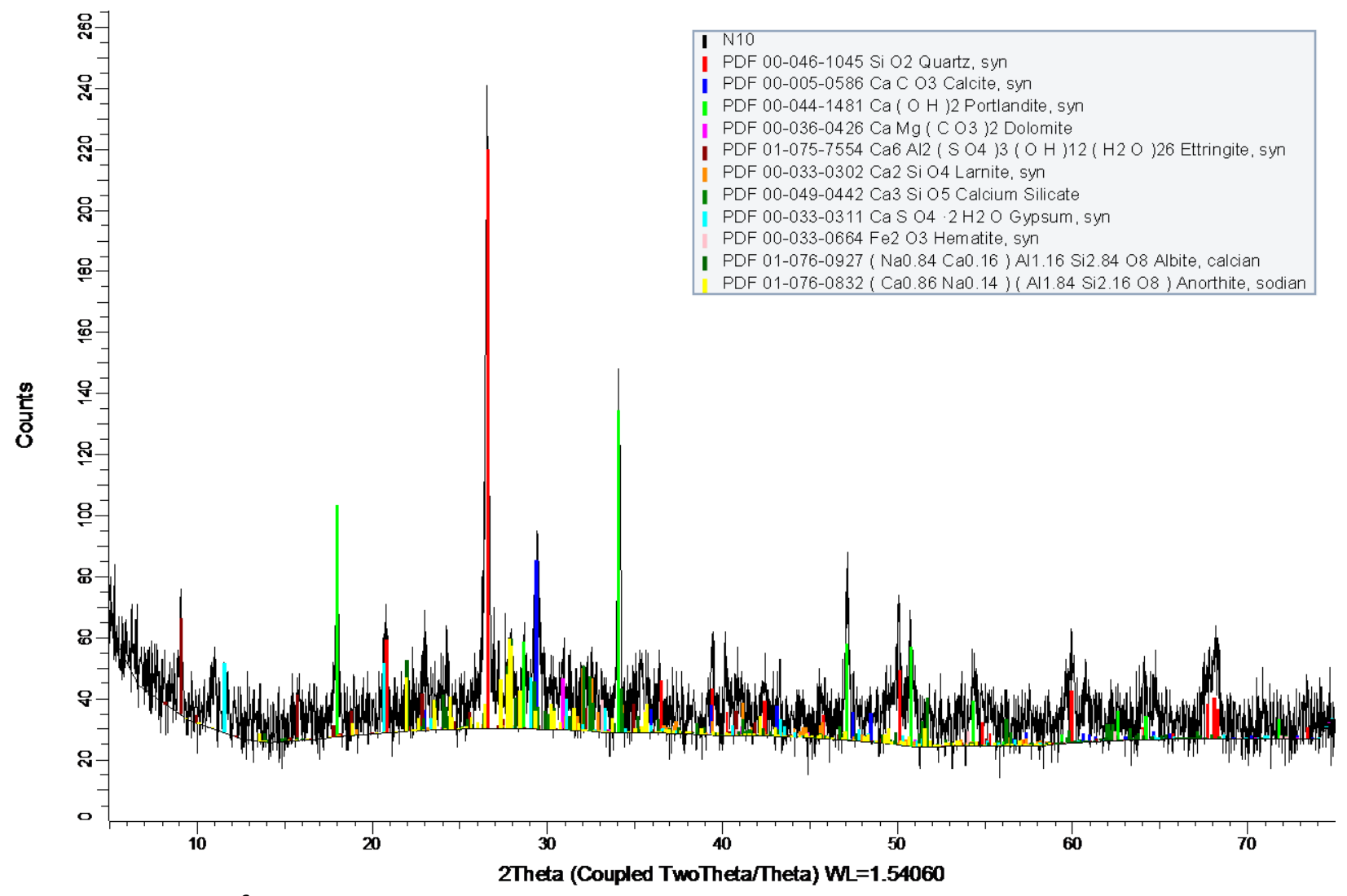

Figure 13. XRD of mix N10

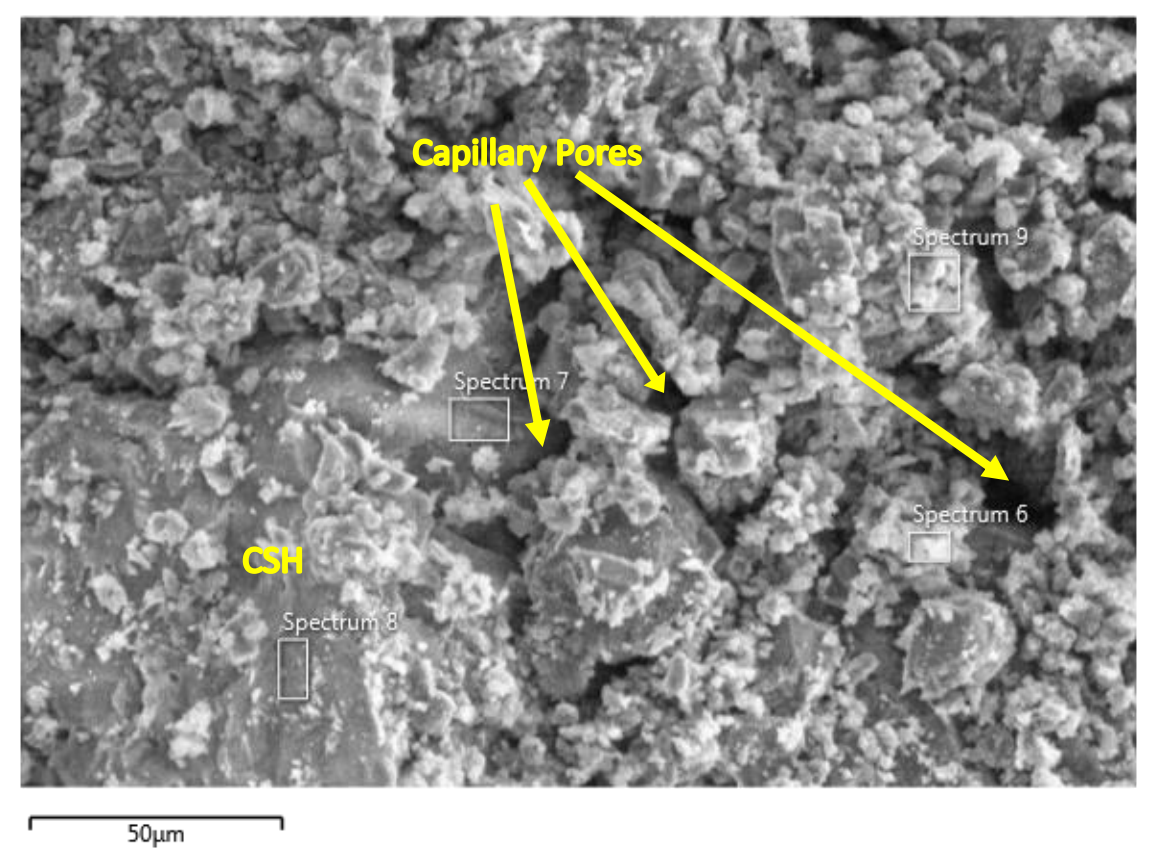

Figure 14. SEM image of N10 

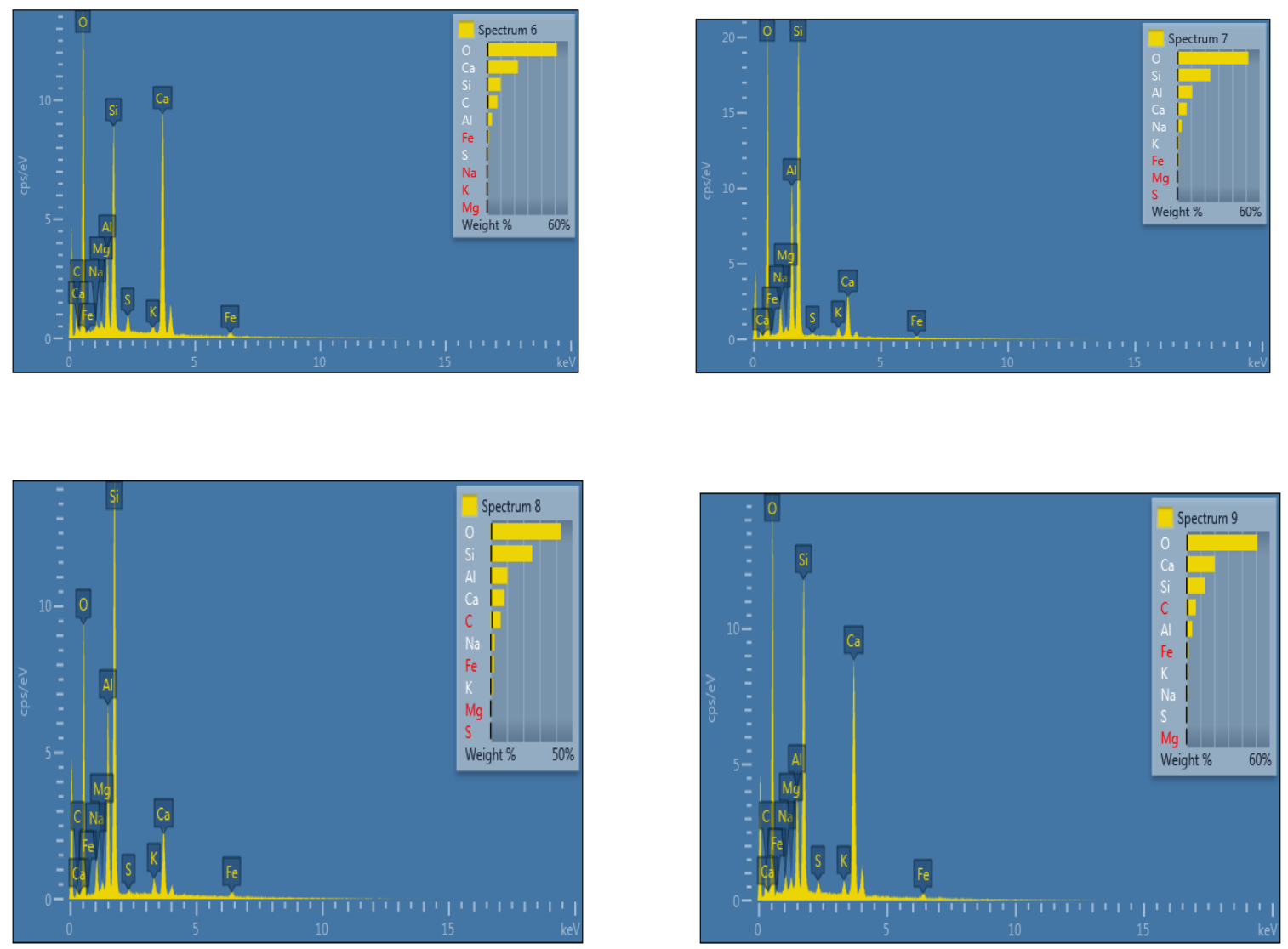

Figure 15. EDS of identified spots on N10 SEM: Spectrum 6, 7, 8 and 9

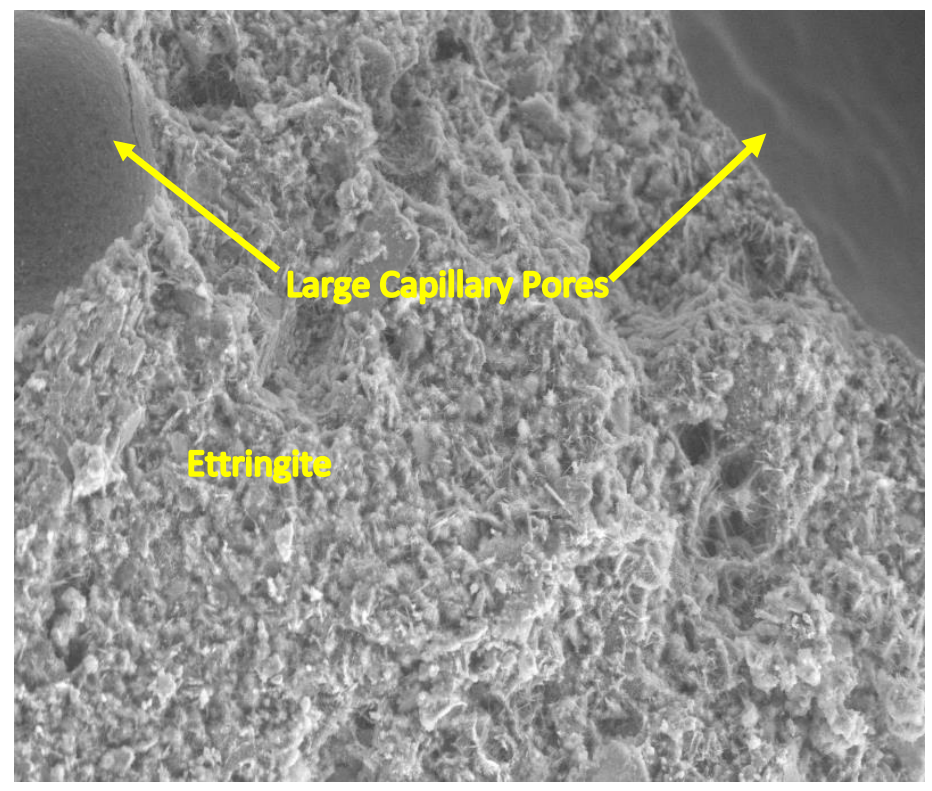

Figure 16. SEM image of reference mortar 


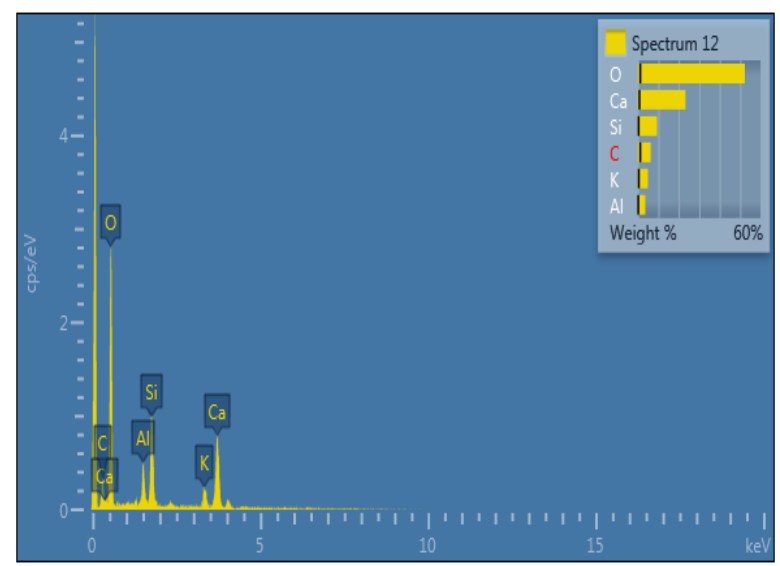

Figure 17. Typical EDS of reference mortar
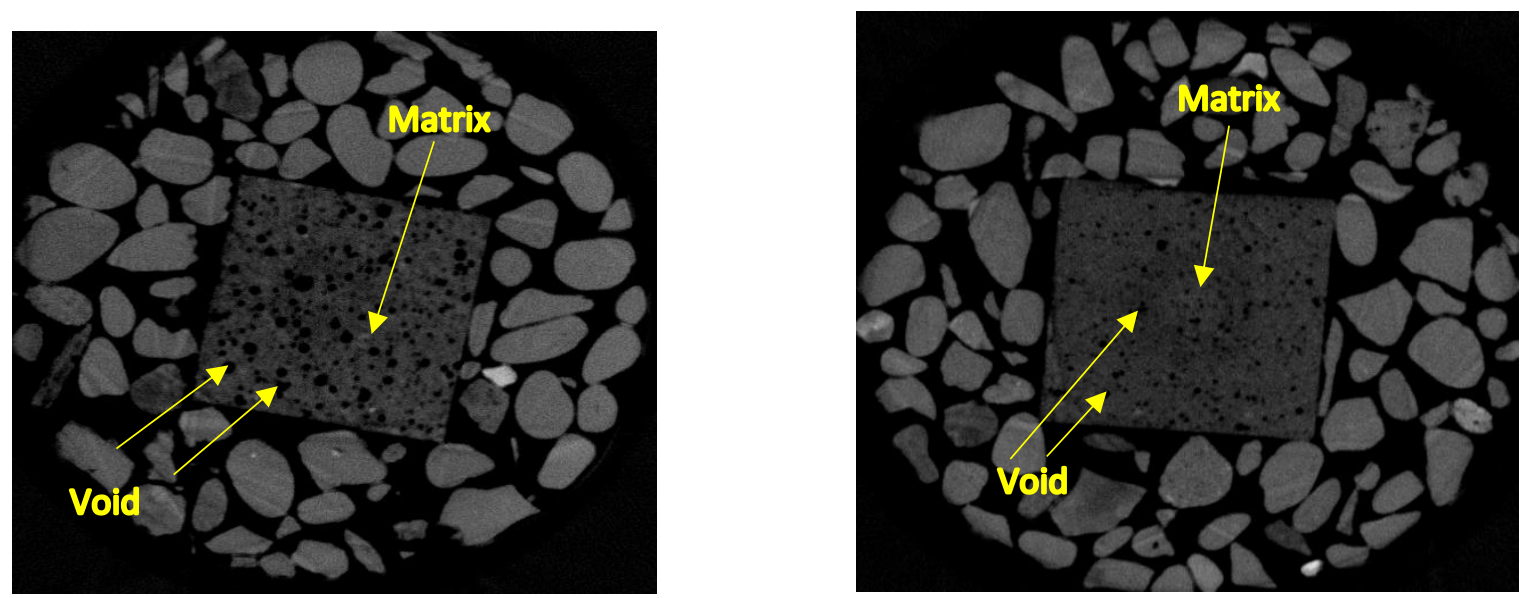

Figure 18. 2D X-ray image of (a) mix N10 (b) reference mortar

\section{Conclusion}

This study has explored the suitability of mortars produced using laterite and ceramic wastes as replacement for cement and sand. Strength properties of the specimens were evaluated and selected samples were further analyzed using microscale tests. Based on the results obtained, the following conclusions are drawn: 
- There was no significant influence on the dry bulk density (DBD) of mortar based on the total substitution of laterite for sand and partial substitution of ceramic powder for cement. However, for mortars made with $100 \%$ ceramic fines, DBD decreased with increasing ceramic powder.

- As far as water absorption by capillary action is concerned, mortars containing $100 \%$ laterite as fine aggregate present higher values, at all ceramic powder levels. It was observed that samples having the lowest dry bulk density, also present appreciable water absorption by capillary action. This was attributed to the water absorption property of laterite, which was the dominant aggregate in those mixes.

- As regards the strength properties, increasing ceramic powder as cement substitute doesn't give any increase in strength for either samples with $100 \%$ laterite or ceramic fines. However, the best strength properties were observed with mortar sample N10, which contains $10 \%$ ceramic powder (as replacement for cement) and 100\% ceramic fine replacement for sand. Thus, the strength in mix N10 was far higher than that of the reference mortar, and this positive performance has been attributed to filler action and relative pozzolanic reaction that took place in the mix. Moreover, the behaviour of the mortars containing large amount of ceramic was ductile in response to loading, compared to the brittle failure seen in other categories of mortar.

- Microstructural analysis of mix N10 and reference mortar has shown that the N10 mortar was characterized by higher 2 theta values at peaks for ettringite, portlandite and calcite, than the reference mortar. Also, the SEM and EDS results clearly suggest that a better compacted structure existed in the N10 mortar than in the reference. Thus, based on the observed results, mortar N10 can serve as a general purpose mortar for construction. 


\section{Acknowledgements}

The principal author would like to express his gratitude to the Commonwealth Scholarship Commission and the University of Nottingham (UoN), UK for sponsoring this research. The technical staff of the concrete laboratory, UoN are appreciated for providing support during the mechanical assessments of mortars. Last but not the list, the authors hereby acknowledge Nigel Neate, Christopher Fox and Elisabeth Steer for assisting with the microscale analysis performed in this study.

\section{References}

[1] Abadou, Y., Mitiche-Kettab, R., Ghrieb, A., 2016. Ceramic waste influence on dune sand mortar performance. Constr. Build. Mater. 125, 703-713. doi:10.1016/j.conbuildmat.2016.08.083

[2] Boukour, S., Benmalek, M.L., 2016. Performance evaluation of a resinous cement mortar modified with crushed clay brick and tire rubber aggregate. Constr. Build. Mater. 120, 473481. doi:10.1016/j.conbuildmat.2016.05.119

[3] Guades, E.J., 2016. Experimental investigation of the compressive and tensile strengths of geopolymer mortar: The effect of sand/fly ash (S/FA) ratio. Constr. Build. Mater. 127, 484493. doi:10.1016/j.conbuildmat.2016.10.030

[4] Herrero, T., Vegas, I.J., Santamar??a, A., San-Jos??, J.T., Skaf, M., 2016. Effect of high-alumina ladle furnace slag as cement substitution in masonry mortars. Constr. Build. Mater. 123, 404-413. doi:10.1016/j.conbuildmat.2016.07.014

[5] Jamil, M., Khan, M.N.N., Karim, M.R., Kaish, A.B.M.A., Zain, M.F.M., 2016. Physical and 
chemical contributions of Rice Husk Ash on the properties of mortar. Constr. Build. Mater. 128, 185-198. doi:10.1016/j.conbuildmat.2016.10.029

[6] Kallel, T., Kallel, A., Samet, B., 2016. Durability of mortars made with sand washing waste. Constr. Build. Mater. 122, 728-735. doi:10.1016/j.conbuildmat.2016.06.086

[7] Kockal, N.U., 2016. Investigation about the effect of different fine aggregates on physical, mechanical and thermal properties of mortars. Constr. Build. Mater. 124, 816-825. doi:10.1016/j.conbuildmat.2016.08.008

[8] Martínez-Lage, I., Velay-Lizancos, M., Vázquez-Burgo, P., Rivas-Fernández, M., VázquezHerrero, C., Ramírez-Rodríguez, A., Martín-Cano, M., 2016. Concretes and mortars with waste paper industry: Biomass ash and dregs. J. Environ. Manage. 181, 863-873. doi:10.1016/j.jenvman.2016.06.052

[9] Mohseni, E., Naseri, F., Amjadi, R., Khotbehsara, M.M., Ranjbar, M.M., 2016. Microstructure and durability properties of cement mortars containing nano-TiO2 and rice husk ash. Constr. Build. Mater. 114, 656-664. doi:10.1016/j.conbuildmat.2016.03.136

[10] Priyanka A, Jadhav, D.K.K., 2013. Effect of replacement of natural sand by manufactured sand on the properties of cement mortar. Res. Artic. 3, 621-628. doi:10.6088/ijcser.2

[11] Rhee, I., Lee, J.S., Kim, Y.A., Kim, J.H., Kim, J.H., 2016. Electrically conductive cement mortar: Incorporating rice husk-derived high-surface-area graphene. Constr. Build. Mater. 125, 632642. doi:10.1016/j.conbuildmat.2016.08.089

[12] Silva, J., de Brito, J., Veiga, R., 2009. Incorporation of fine ceramic in mortars. Constr. Build. Mater. 23, 556-564.

[13] Torres, I., Matias, G., 2016. Sustainable mortars for rehabilitation of old plasters. Eng. Struct. doi:10.1016/j.engstruct.2016.07.009

[14] Wang, C.-C., 2016. Modelling of the compressive strength development of cement mortar with furnace slag and desulfurization slag from the early strength. Constr. Build. Mater. 128, 108-117. doi:10.1016/j.conbuildmat.2016.10.083 
[15] Zahedi, M., Ramezanianpour, A.A., Ramezanianpour, A.M., 2015. Evaluation of the mechanical properties and durability of cement mortars containing nanosilica and rice husk ash under chloride ion penetration. Constr. Build. Mater. 78, 354-361. doi:10.1016/j.conbuildmat.2015.01.045

[16] Alves, A., Vieira, T., de Brito, J., Correia, J., 2014. Mechanical properties of structural concrete with fine recycled ceramic aggregates. Constr. Build. Mater. 64, 103-113.

[17] Pereira-de-Oliveira, L., Castro-Gomes, J., Santos, P., 2012. The potential pozzolanic activity of glass and red-clay ceramic waste as cement mortars components. Constr. Build. Mater. 197-203.

[18] Medina, C., Frias, M., de Rojas, M., Sánchez, C., Thomas, J., 2012. Gas permeability in concrete containing recycled ceramic sanitary ware aggregate,. Constr. Build. Mater. 37, 597-605.

[19] Partyka, J., Sitarz, M., Leśniak, M., Gasek, K., Jeleń, P., 2015. The effect of SiO2/Al2O3 ratio on the structure and microstructure of the glazes from SiO2-Al 2O3-CaO-MgO-Na2O-K2O system. Spectrochim. Acta - Part A Mol. Biomol. Spectrosc. 134, 621-630. doi:10.1016/j.saa.2014.06.068

[20] Sadik, C., Amrani, I. El, Albizane, A., 2014. Journal of Asian Ceramic Societies Recent advances in silica-alumina refractory: A review. Integr. Med. Res. 2, 83-96. doi:10.1016/j.jascer.2014.03.001

[21] Awoyera, P.O., Akinmusuru, J.O., Ndambuki, J.M., 2016. Green concrete production with ceramic wastes and laterite. Constr. Build. Mater. 117, 29-36. doi:10.1016/j.conbuildmat.2016.04.108

[22] Osunade, J.A., 2002. Effect of replacement of lateritic soils with granite fines on the compressive and tensile strengths of laterized concrete. Build. Environ. 37, 491-496. doi:10.1016/S0360-1323(01)00049-X 
[23] Muthusamy, K., Kamaruzaman, N.W., Ismail, M.A. et al., 2015. Durability performance of concrete containing laterite aggregates. KSCE J. Civ. Eng. 19, 2217. doi:10.1007/s12205015-0279-2

[24] Fola, L., Osunade, J. A., and Adewale, A. O., 1990. Short-term studies on the durability of laterized concrete and laterite-cement mortars. Build. Environ. 25, 77-83. doi: 10.1016/0360-1323(90)90044-R

[25] Udeoyo, F. F., Iron, U. H., and Odim, O. O., 2006. Strength performance of laterized concrete. Constr. Build. Mat. 20, 1057-1062. doi: 10.1016/j.conbuildmat.2005.03.002

[26] Kasthurba, A.K., Santhanam, M., Achyuthan, H., 2008. Investigation of laterite stones for building purpose from Malabar region, Kerala, SW India - Chemical analysis and microstructure studies. Constr. Build. Mater. 22, 2400-2408. doi:10.1016/j.conbuildmat.2006.12.003

[27] Kulovaná, T., Zbysek Pavlik, Z., 2016. Characterization of composite materials based on cement-ceramic powder blended binder, in: AIP Conference Proceedings 1738, 280004.

[28] Awoyera, P. O., Akinmusuru, J. O., Moncea, A., 2017. Hydration mechanism and strength properties of recycled aggregate concrete made using ceramic blended cement. Cogent Eng. 4. Doi:10.1080/23311916.2017.1282667

[30] BS EN 1015-10, 1999. Methods of test for mortar for masonry -Part 10: Determination of dry bulk density of hardened mortar. Br. Stand.

[29] BS EN 1015-11, 1999. Methods of test for mortar for masonry - Part 11: Determination of flexural and compressive strength of hardened mortar. Br. Stand.

[31] BS EN 1015-18, 1999. Methods of test for mortar for masonry -Part 18: Determination of water absorption coefficient due to capillary action of hardened mortar. Br. Stand.

[32] Stutzman, P., Clifton, J., 1999. Specimen Preparation for Scanning Electron Microscope, in: Proceedings of the Twenty-First International Conference on Cement Microscopy. Las Vegas, Nevada, pp. 10-22. 
[33] Jayalath, A., San Nicolas, R., Sofi, M., Shanks, R., Ngo, T., Aye, L., Mendis, P., 2016. Properties of cementitious mortar and concrete containing micro-encapsulated phase change materials. Constr. Build. Mater. 120, 408-417. doi:10.1016/j.conbuildmat.2016.05.116

[34] Mortar Industrial Association, 2015. A guide to BS EN 998 -1 and BS EN 998 - 2. Miner. Prod. Assoc. Ltd Data sheet.

[35] Chindaprasirt, P., Rukzon, S., 2014. Strength and chloride resistance of the blended Portland cement mortar containing rice husk ash and ground river sand. Mater. Struct.

[36] Nazari, A. and Riahi, S., 2012. The effect of aluminium oxide nanoparticles on the compressive strength and structure of self-compacting concrete. Mag. Conc. Res. 2012 64:1, 71-82, DOI: http://dx.doi.org/10.1680/macr.10.00106

[37] Mohammed, M.K., Dawson, A.R., Thom, N.H., 2013. Production, microstructure and hydration of sustainable self-compacting concrete with different types of filler. Constr. Build. Mater. 49, 84-92. doi:10.1016/j.conbuildmat.2013.07.107

[38] Promentilla, M.A.B., Sugiyama, T., 2010. X-Ray Microtomography of Mortars Exposed to Freezing-Thawing Action. J. Adv. Concr. Technol. 8, 97-111. doi:10.3151/jact.8.97 